\title{
Analysis of six chloroplast genomes provides insight into the evolution of Chrysosplenium (Saxifragaceae)
}

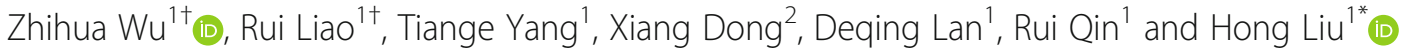

\begin{abstract}
Background: Chrysosplenium L. (Saxifragaceae) is a genus of plants widely distributed in Northern Hemisphere and usually found in moist, shaded valleys and mountain slopes. This genus is ideal for studying plant adaptation to low light conditions. Although some progress has been made in the systematics and biogeography of Chrysosplenium, its chloroplast genome evolution remains to be investigated.
\end{abstract}

Results: To fill this gap, we sequenced the chloroplast genomes of six Chrysosplenium species and analyzed their genome structure, GC content, and nucleotide diversity. Moreover, we performed a phylogenetic analysis and calculated non-synonymous (Ka) /synonymous (Ks) substitution ratios using the combined protein-coding genes of 29 species within Saxifragales and two additional species as outgroups, as well as a pair-wise estimation for each gene within Chrysosplenium. Compared with the outgroups in Saxifragaceae, the six Chrysosplenium chloroplast genomes had lower GC contents; they also had conserved boundary regions and gene contents, as only the rp/32 gene was lost in four of the Chrysosplenium chloroplast genomes. Phylogenetic analyses suggested that the Chrysosplenium separated to two major clades (the opposite group and the alternate group). The selection pressure estimation (Ka/Ks ratios) of genes in the Chrysosplenium species showed that matK and ycf2 were subjected to positive selection.

Conclusion: This study provides genetic resources for exploring the phylogeny of Chrysosplenium and sheds light on plant adaptation to low light conditions. The lower average GC content and the lacking gene of rp/32 indicated selective pressure in their unique habitats. Different from results previously reported, our selective pressure estimation suggested that the genes related to photosynthesis (such as ycf2) were under positive selection at sites in the coding region.

Keywords: Saxifragaceae, Chrysosplenium, Chloroplast genome, Opposite leaves, Alternate leaves, Phylogenomics

\footnotetext{
* Correspondence: liuhong@mail.scuec.edu.cn

${ }^{\dagger}$ Zhihua Wu and Rui Liao contributed equally to this work.

${ }^{1}$ Hubei Provincial Key Laboratory for Protection and Application of Special Plant Germplasm in Wuling Area of China, Key Laboratory of State Ethnic Affairs Commission for Biological Technology, College of Life Sciences, South-Central University for Nationalities, Wuhan 430074, Hubei, China Full list of author information is available at the end of the article
}

(c) The Author(s). 2020 Open Access This article is licensed under a Creative Commons Attribution 4.0 International License, which permits use, sharing, adaptation, distribution and reproduction in any medium or format, as long as you give appropriate credit to the original author(s) and the source, provide a link to the Creative Commons licence, and indicate if changes were made. The images or other third party material in this article are included in the article's Creative Commons licence, unless indicated otherwise in a credit line to the material. If material is not included in the article's Creative Commons licence and your intended use is not permitted by statutory regulation or exceeds the permitted use, you will need to obtain permission directly from the copyright holder. To view a copy of this licence, visit http://creativecommons.org/licenses/by/4.0/. The Creative Commons Public Domain Dedication waiver (http://creativecommons.org/publicdomain/zero/1.0/) applies to the data made available in this article, unless otherwise stated in a credit line to the data. 


\section{Background}

Challenging environments may impose selective pressure on genes, which could leave a footprint of natural selection in genes involved in adaptation to the environment. The chloroplast genome is typically quadripartite in structure, containing a large single copy (LSC) and a small single copy (SSC) separated by a pair of inverted repeats (IR). It is widely used for chloroplast inheritance, domestication studies, phylogeny and adaptative evolution [1-3]. Adaptive evolution is considered as the improved adaptability of species for changing environmental conditions during their evolutionary processes. And it is driven by evolutionary processes such as natural selection, which act on genetic variations produced by genetic recombination, gene mutations, and gene flow [4]. Strong purifying selection detected rather than expected positive selection in chloroplast genome of the green alga (Ostreobium quekettii) facilitated its extremely low light adaptation [5]. This study contributed to our understanding of plant adaptive evolution. However, to our knowledge, a comparative analysis of chloroplast genomes of angiosperms with low light requirements has not been conducted.

Chrysosplenium L. is a genus of Saxifragaceae and belongs to the subfamily Saxifragoideae according to the APG IV [6]. The genus plays an important role in the phylogeny of Saxifragaceae, comprises about 79 perennial herbs [7], and mainly occurs in the northern hemisphere, with the highest species diversity in East Asia; only two species, Chrysosplenium valdivicum Hook and Chrysosplenium macranthum Hook, are found in the Southern Hemisphere [8, 9]. Thirty-six species and fifteen variants have been recorded in China $[10,11]$. Chrysosplenium is divided into two subgenera according to the leaf arrangement: Alternifolia Franchet with alternate leaves and Oppositifolia Franchet with opposite leaves [8, 10, 12]. The genus was regarded as a typical group with floristic disjunction and is important for studying speciation [13, 14]. Chrysosplenium (Saxifragaceae) is usually found in shaded valleys and mountain slopes and, compared with other genera within Saxifragaceae, this genus has the lowest light requirement $[8,15]$. Therefore, examination of the chloroplast genomes of Chrysosplenium species may provide insight into the impacts of low light in angiosperms.

Nuclear markers (such as the internal transcribed spacer, ITS) of the ribosomal DNA, and chloroplast markers were employed to determine the molecular phylogeny of Chrysosplenium [16, 17]. Compared to nuclear markers, the chloroplast genome possesses highly conserved DNA sequences and a lower substitution level (especially in inverted repeat regions). Therefore, the chloroplast genome is ideal for phylogenetic inference at the species and higher levels [9, 17-20].

In this study, we aimed to provide a comprehensive insight into the evolution of the chloroplast genomes of several Chrysosplenium species. First, we sequenced the chloroplast genomes of six Chrysosplenium species in addition to a previous study [21]. Next, we conducted comparative chloroplast genome analyses for these six genomes, plus four Saxifragaceae chloroplast genomes from GenBank. Then, we constructed a phylogeny of Chrysosplenium using chloroplast genomes of 29 species within Saxifragales and two outgroups. Finally, we estimated selective pressures to investigate whether the genes related to photosynthesis in Chrysosplenium are under purifying selection or positive selection.

\section{Results \\ Organization of the Chloroplast Genomes of Chrysosplenium species}

The chloroplast genomes of the Chrysosplenium species contain the typical quadripartite structures (Fig. 1), which include a large single copy (LSC), two inverted repeats (IR) and a small single copy (SSC) region. The seven Chrysosplenium chloroplast genomes ranged from $151,679 \mathrm{bp}$ to $153,460 \mathrm{bp}$ in length (see Table 1 for details), with IRs 25,974-26,224 bps, LSCs 82,771-83,752 bps and SSCs 16,960-17,342 bps. Each Chrysosplenium chloroplast genome encoded 30 transfer RNAs (tRNAs) and 4 ribosomal RNAs (rRNAs). Each genome also includes 79 functional proteins (Table 2) encoding genes except for C. macrophyllum, C. flagelliferum, C. alternifolium, C. ramosum, which lacked rpl32. By homolog and expression analysis of chloroplast rpl32 in C. sinicum (Cp_rpl32), another homolog (Nu_rpl32) was also identified nuclear genome of $C$. sinicum, and the expression value (4.86 FPKMs) of Nu_rpl32 is much lower than that (20,835.9 FPKMs) of Cp_rpl32 (Additional file 1: Supplementary Figure S1). In total, each chloroplast genome includes 113 (rpl32 present) or 112 (rpl32 loss) genes. The rps12 gene in Chrysosplenium was recognized as a trans-spliced gene, with the first exon located in the LSC region and the other one or two exons distributed in the IR regions. In addition, 17 introncontaining genes were also detected (Additional file 2: Supplementary Table S4). The chloroplast genome size and gene content neither significantly diverged between Oppositifolia and Alternifolia subgenera (Table 1) nor significantly diverged between Chrysosplenium and other genera of Saxifragaceae.

\section{GC content, nucleotide diversity, and repeat analysis}

When we compared the total GC content of the chloroplast genomes of Chrysosplenium species with that of the chloroplast genomes of the three non-Chrysosplenium Saxifragaceae species (S. stolonifera, B. scopulosa, and $O$. rupifraga), we found the Chrysosplenium species have the lowest total GC contents (<37.5\%) (Fig. 2 and Additional file 2: Supplementary Table S5). In addition, 


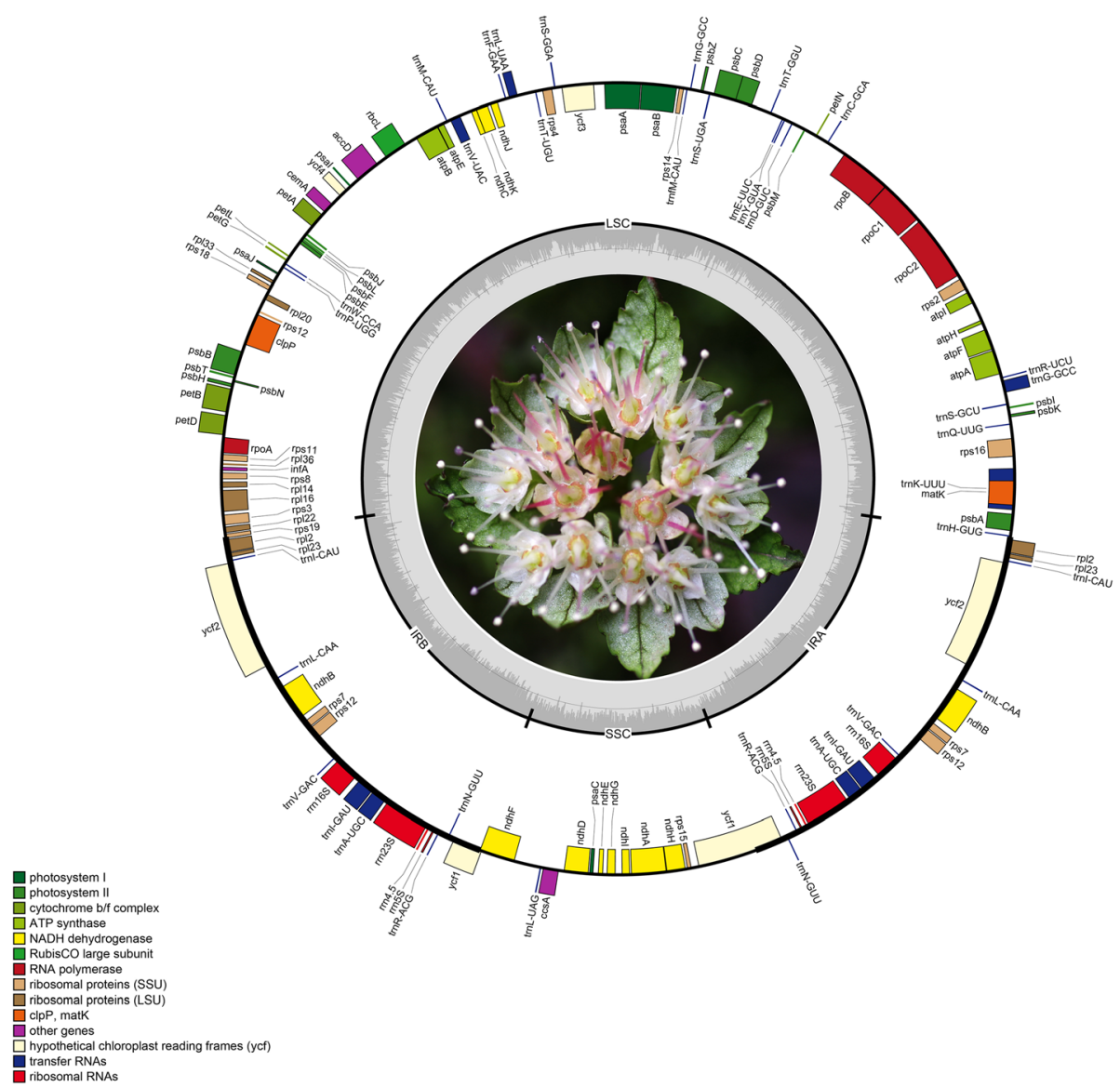

Fig. 1 Gene map of the Chrysosplenium macrophyllum chloroplast genomes. Genes inside the circle are transcribed clockwise, genes outside are transcribed counter-clockwise. Genes are color-coded to indicate functional groups. The dark gray area in the inner circle corresponds to GC content while the light gray corresponds to the adenine-thymine (AT) content of the genome. The small (SSC) and large (LSC) single copy regions and inverted repeat (IRa and $\mathrm{IRb}$ ) regions are noted in the inner circle

Table 1 General information and comparison of chloroplast genomes of Saxifragaceae species

\begin{tabular}{|c|c|c|c|c|c|c|c|}
\hline Characteristic & C. macrophyllum & C. flagelliferum & C. alternifolium & C. kamtschaticum & C. ramosum & C. sinicum & C. aureobracteatum \\
\hline Size (base pair, bp) & 152,837 & 151,679 & 152,619 & 152,561 & 153,460 & 153,427 & 153,102 \\
\hline LSC length (bp) & 83,583 & 82,771 & 83,524 & 83,175 & 83,670 & 83,745 & 83,753 \\
\hline SSC length (bp) & 17,264 & 16,960 & 17,111 & 16,986 & 17,342 & 17,236 & 17,317 \\
\hline IR length (bp) & 25,995 & 25,974 & 25,992 & 26,200 & 26,224 & 26,223 & 26,016 \\
\hline Number of genes & 112 & 112 & 112 & 113 & 112 & 113 & 113 \\
\hline Protein-coding genes & 78 & 78 & 78 & 79 & 78 & 79 & 79 \\
\hline rRNA genes & 4 & 4 & 4 & 4 & 4 & 4 & 4 \\
\hline tRNA genes & 30 & 30 & 30 & 30 & 30 & 30 & 30 \\
\hline LSC GC\% & 35.33 & 35.26 & 35.35 & 35.28 & 35.24 & 35.05 & 35.20 \\
\hline SSC GC\% & 31.42 & 31.37 & 31.40 & 31.46 & 31.64 & 31.27 & 31.16 \\
\hline IR GC\% & 42.89 & 42.87 & 42.86 & 42.71 & 42.69 & 42.75 & 42.85 \\
\hline Lacking gene & rpl32 & rpl32 & $r p / 32$ & & rpl32 & & \\
\hline
\end{tabular}


Table 2 Genes encoded in the C. macrophyllum chloroplast genome

\begin{tabular}{|c|c|}
\hline Group of Genes & Gene Name \\
\hline tRNA genes & 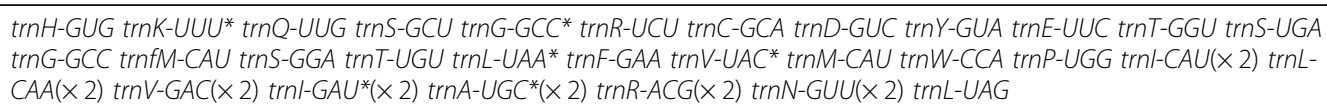 \\
\hline rRNA genes & $r r n 16(\times 2) r r n 23(\times 2) r r n 4.5(\times 2) r r n 5(\times 2)$ \\
\hline Ribosomal small subunit & rps $16^{*}$ rps 2 rps 14 rps4 rps 18 rps $12^{* *}(\times 2)$ rps 11 rps8 rps3 rps 19 rps7(×2) rps 15 \\
\hline Ribosomal large subunit & rp/33 rpl20 rp/36 rpl14 rp/16* rp/22 rp/2(×2) rp/23(×2) \\
\hline $\begin{array}{l}\text { DNA-dependent RNA } \\
\text { polymerase }\end{array}$ & rpoC2 rрoC1* rpoB rpoA \\
\hline Photosystem I & psaB psaA psal psaJ psaC \\
\hline Large subunit of rubisco & $r b c L$ \\
\hline Photosystem ॥ & psbA psbK psbl psbM psbC psbZ psbG psbJ psbL psbF psbE psbB psbT psbN psbH \\
\hline NADH dehydrogenase & $n d h J$ ndhK $n d h C n d h B^{*}(\times 2) n d h F$ ndhD ndhE ndhG ndhl ndhA* ndhH \\
\hline Cytochrome b/f complex & petN petA petL petG petB* petD* \\
\hline ATP synthase & $\operatorname{atp} A$ atpF* atpH atpl atpE atpB \\
\hline Maturase & matk \\
\hline $\begin{array}{l}\text { Subunit of acetyl-CoA } \\
\text { carboxylase }\end{array}$ & $\operatorname{acc} D$ \\
\hline Envelope membrane protein & cemA \\
\hline Protease & $c l p P^{* *}$ \\
\hline Translational initiation factor & $\operatorname{infA}$ \\
\hline C-type cytochrome synthesis & $\operatorname{ccs} A$ \\
\hline $\begin{array}{l}\text { Conserved open reading } \\
\text { frames (ycf) }\end{array}$ & $y c f 3^{* *} y c f 4$ ycf2(×2) ycf1(×2) \\
\hline
\end{tabular}

Genes with one or two introns are indicated by one $\left(^{*}\right)$ or two asterisks $\left({ }^{* *}\right)$, respectively. Genes in the IR regions are followed by the $(\times 2)$ symbol.

Chrysosplenium has the lowest GC contents $(<29.7 \%)$ at the third codon position (GC3). Within the Chrysosplenium species, the GC contents in subgenus Oppositifolia were slightly lower than those in subgenus Alternifolia, regardless of the total GC contents or those in GC3.

The IR regions were more conserved than the LSC and SSC regions, with average Pi values of 0.00586 in IR regions, 0.01760 in the $\mathrm{LSC}$ region, and 0.01900 in the SSC region (Additional file 2: Supplementary Table S6 and Additional file 3: Supplementary Figure S2). In the LSC region, $p s b T$ has the highest $\mathrm{Pi}$ value of 0.22159, followed by trnG-GCC with Pi value of 0.10369 .

Among the mono-, di-, tri-, tetra-, penta-, and hexanucleotide categories of SSRs in the chloroplast genomes of the Chrysosplenium species, mono-nucleotide repeats were the most common (Additional File 4: Supplementary Table S7 and Additional File 5: Supplementary Figure S3A) ranging from $42.42 \%$ (C. sinicum) to $61.29 \%$ (C. flagelliferum). Hexa-nucleotide repeats account for the lowest proportion of SSRs in C. ramosum, C. sinicum, and C. flagelliferum. Chrysosplenium species contained fewer SSRs than B. scopulosa and O. rupifraga. Among the four repeat types, the most common repeat type was palindromic repeats, which ranged from $53.13 \%$ in $C$. aureobracteatum to $42.42 \%$ in $C$. macrophyllum (Additional File 4: Supplementary Table S8 and Additional File 5: Supplementary Figure S3B).

\section{Boundary regions and comparative analysis}

When comparing the chloroplast genomes of Chrysosplenium species, we found that IR/LSC junctions of IRb are largely located between $r p l 2$ and $r p s 19$ (Fig. 3). Moreover, the overlap of $y c f 1$ pseudogenes and $n d h F$ appeared in different locations among the Chrysosplenium species: in the region of the SSC for C. ramosum, and at the IRb/SSC border for the other five species. C. alternifolium did not contain the $y c f 1$ pseudogene. The $y c f 1$ genes were sited at the SSC/IRa boundary and the length of $y c f 1$ ranged from 5402 to 5546 bps. The trnH genes of the seven Chrysosplenium species were located in the LSC region, 2-19 bp away from the IRa-LSC border.

When comparing the genome boundaries of the Chrysosplenium species to the other three non-Chrysosplenium species of Saxifragaceae, $n d h F$ was at the IRb/SSC boundary in most species of Chrysosplenium, except for C. ramosum, which showed contraction of the SSC and expansion of IRb. In addition, S. stolonifera was slightly different from the other two non-Chrysosplenium species in Saxifragaceae. In S. stolonifera, the contraction of the LSC region resulted in the rpl22 gene being at the 


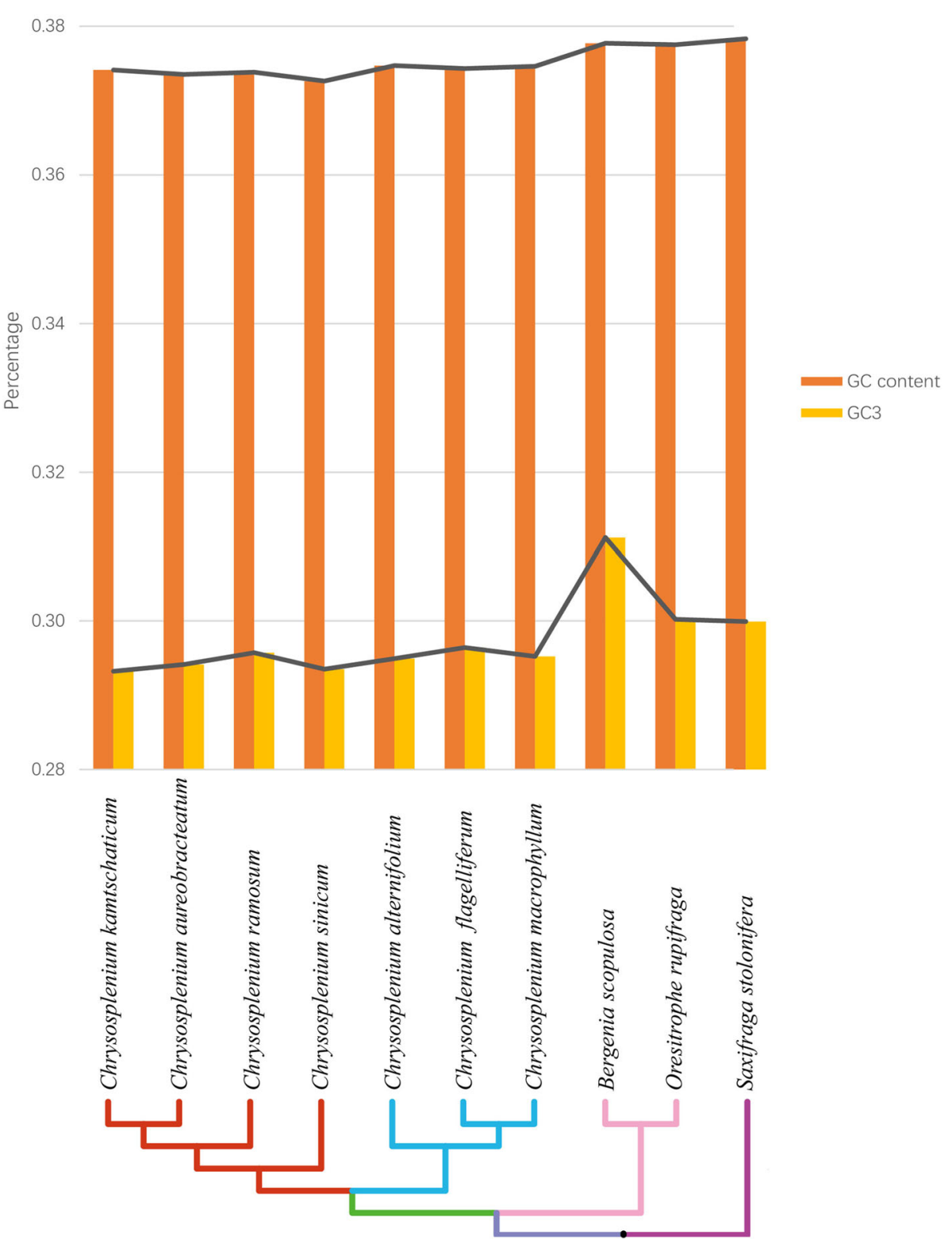

Fig. 2 Changes in plastid GC content of Saxifragaceae. This graph shows the total GC content (orange bar and black line) and the third codon position GC content (yellow bar and gray line) of each species. The subgenera of Oppositifolia and Alternifolia are colored by red and blue, respectively

IRb/LSC junction, which placed the whole rps19 gene in the IRb region. The rps19 pseudogenes were also found in the IRa region in S. stolonifera and B. scopulosa. When these data were combined with the phylogenetic tree of the three clades (S. stolonifera, B. scopulosa and O. rupifraga, and Chrysosplenium) inferred from whole-chloroplast protein-coding genes (Fig. 3), we found that the chloroplast genome structure within Chrysosplenium species is not strongly conserved, although the gene content is conserved.

LAGAN and Shuffle-LAGAN gave very similar results in the genetic divergence among the chloroplast genomes of Saxifragaceae species (Fig. 4 and Additional File 6: Supplementary
Figure S4). The chloroplast genomes of the Chrysosplenium species were more conserved when compared with the three non-Chrysosplenium species of Saxifragaceae, and the intergenic spacer (IGS) regions had the highest levels of divergence: trnK-rps16, rps16-trnQ, rpoB-trnC, petN-psbM, trnT-psbD, psbZ-trnG, trnT-trnL, accD-psaI, ycf4-cemA, ndhF-rpl32, and rps15-ycf1. In addition, we found some highly variable coding sequences ( $n d h D, y c f 2$, $n d h A$, and $y c f 1$ ), and the IR regions were more conserved than LSC and SSC regions in all the species tested. We also found slight difference for $r p o C 2$, $y c f 2$, and $y c f 1$, which correspond to the difference between the Alternifolia and Oppositifolia subgenera. 


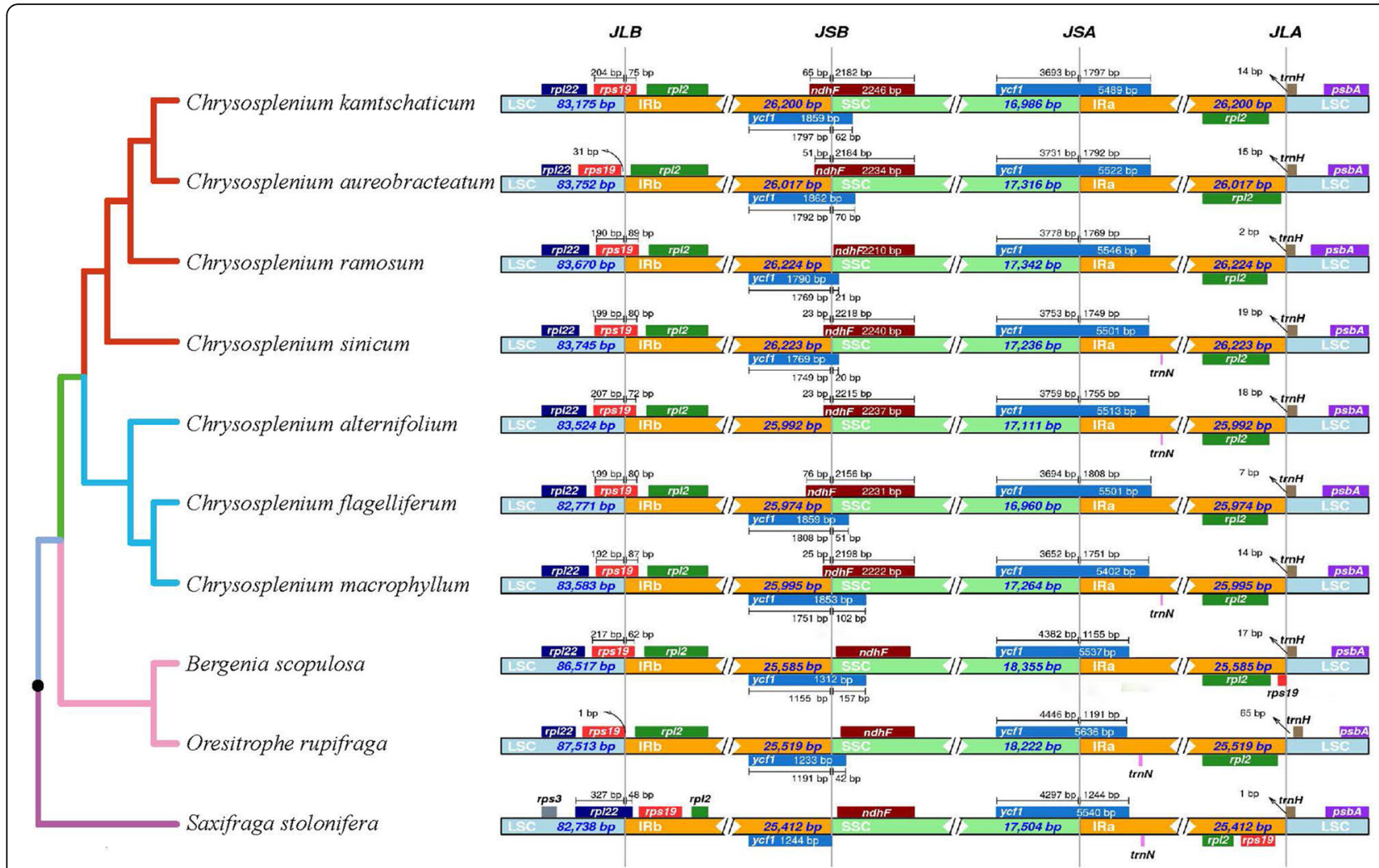

Fig. 3 Comparison of the borders of the LSC, SSC, and IR regions among ten chloroplast genomes. JLB, JSB, JSA and JLA denote the junction sites of LSC/Rb, IRb/SSC, SSC/IRa and IRa/LSC, respectively

\section{Selective pressure analyses}

We calculated the $\mathrm{Ka} / \mathrm{Ks}$ ratios, the ratios of the rate of non-synonymous substitutions $(\mathrm{Ka})$ to the rate of synonymous substitutions (Ks), at the species level by concatenating all of the 79 genes into a super-matrix. In Chrysosplenium species, the $\mathrm{Ka} / \mathrm{Ks}$ ratios were around 0.2 . This result suggested that at the whole-chloroplast protein level, the Chrysosplenium species have been subjected to a stronger purifying selection (Fig. 5, Additional File 4: Supplementary Table $S 9$ and Additional File 4: Supplementary Table S10).

$\mathrm{The} \mathrm{Ka} / \mathrm{Ks}$ ratios were also calculated for all of the 79 protein-coding genes of the ten chloroplast genomes of Chrysosplenium separately (Fig. 6 and Additional File 4: Supplementary Table S7). Two genes (matK, ycf2) had Ka/ Ks ratios around 1.0 in most species, implying possible positive selection. Specially, matK showed an average Ka/Ks ratio of 0.74 when compared with C. ramosum. Among the Chrysosplenium species, $y c f 2$ often had a ratio higher than 0.8 . Most of the other genes had a $\mathrm{Ka} / \mathrm{Ks}$ ratio range from 0.10.3, implying strong purification (Additional File 4: Supplementary Table S10).

Sixty-six single-copy genes were used for selective pressure estimation with the branch-site model (Additional File 4: Supplementary Table S9 and Supplementary Table S11). We found that matK was positively selected in Chrysosplenium with the $p$-value $=0.022$ and the Bayes Empirical Bayes (BEB) posterior probability for one amino acid site (117S, from polar Ser to non-polar Val) larger than 0.972. And the gene of $y c f 2$ was also positively selected in Chrysosplenium with $p$-value $=0.00003$ and the BEB posterior probability for 0.953 in $1028 \mathrm{~K}$ (from Lys to Leu). In addition, positively selected sites were detected for 18 genes (atpB, atpE, atpF, atpI, cemA, clpP, matK, ndhC, ndhE, ndhF, ndhH, ndhK, petA, $p s a B, p s b H, p s b J, p s b N$, rps14, rps16) (Fig. 7 and Additional File 4: Supplementary Table S9).

\section{Phylogenetic analysis}

Phylogenetic analyses yielded a well-supported phylogeny of Saxifrageles with most of the nodes having maximum likelihood (ML) bootstrap support values $>95$ and bayesian inference (BI) posterior probabilities $=1$ (Fig. 8). The topologies yielded from ML analysis and BI analysis were completely identical. The topology of Saxifragales in our study was similar to the APG IV system [6] with Saxifragaceae closer to Iteaceae, phylogenetically. And, Chrysosplenium was divided into two clades corresponding to the two subgenera (Alternifolia and Oppositifolia) in our phylogenetic tree. 


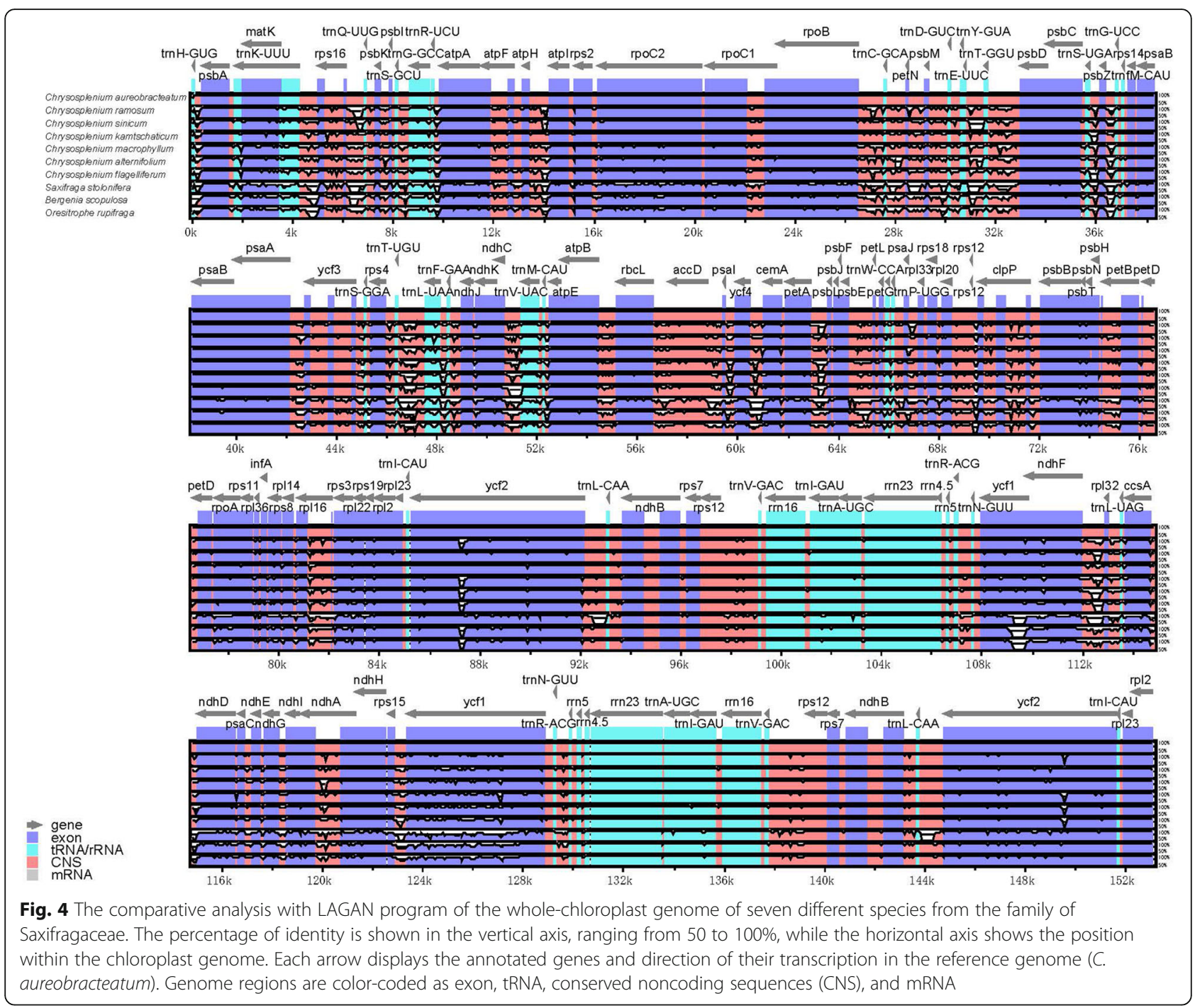

\section{Discussion}

Gene numbers were slightly different due to the loss of rpl32 or transfer of the gene to the nucleus [22-26]. The gene transfer and its dormant expression in Alternifolia of Chrysosplenium could be explained by the decreased demand on photosynthesis and plastid translational capacity, which increased the success rate of gene transfer to the nucleus [27]. Based on the previous study and our results, we speculate the rpl32 gene might transfer to the nucleus due to the adaptation for the specific habitat of Chrysosplenium, although this hypothesis remains to be verified by experiments.

Lower GC contents in Chrysosplenium chloroplast genomes compared to other Saxifragaceae members can be explained by the natural selection [28]. DNA sequences of closely related species from different environments show marked differences in GC content, which has a direct impact on the amino acid sequences of the proteins in the respective environments [29]. Genes with low GC contents are more prone to be transcribed than those with high GC content as GC pairs have three hydrogen bonds, making them more stable than AT pairs with two hydrogen bonds [30]. Therefore, the selective pressure of the unique habitat of Chrysosplenium species (insufficient light energy) resulted in the lower overall GC contents and GC3 contents in their chloroplast genomes.

Compared with other genera within Saxifragaceae, the genus has the lowest light requirement. Among the 79 chloroplast genes in plants, 46 are related to photosynthesis pathway (Table 2) [31]. Genes related to a specific environment are normally assumed to be under positive selection [32]. This assumption was widely used to detect genes related to environmental adaptation [33]. Our expectation was that the 46 genes were under positive selection. However, the lower $\mathrm{Ka} / \mathrm{Ks}$ ratios at the chloroplast genome level within the Chrysosplenium species compared to non-Chrysosplenium species indicated that 


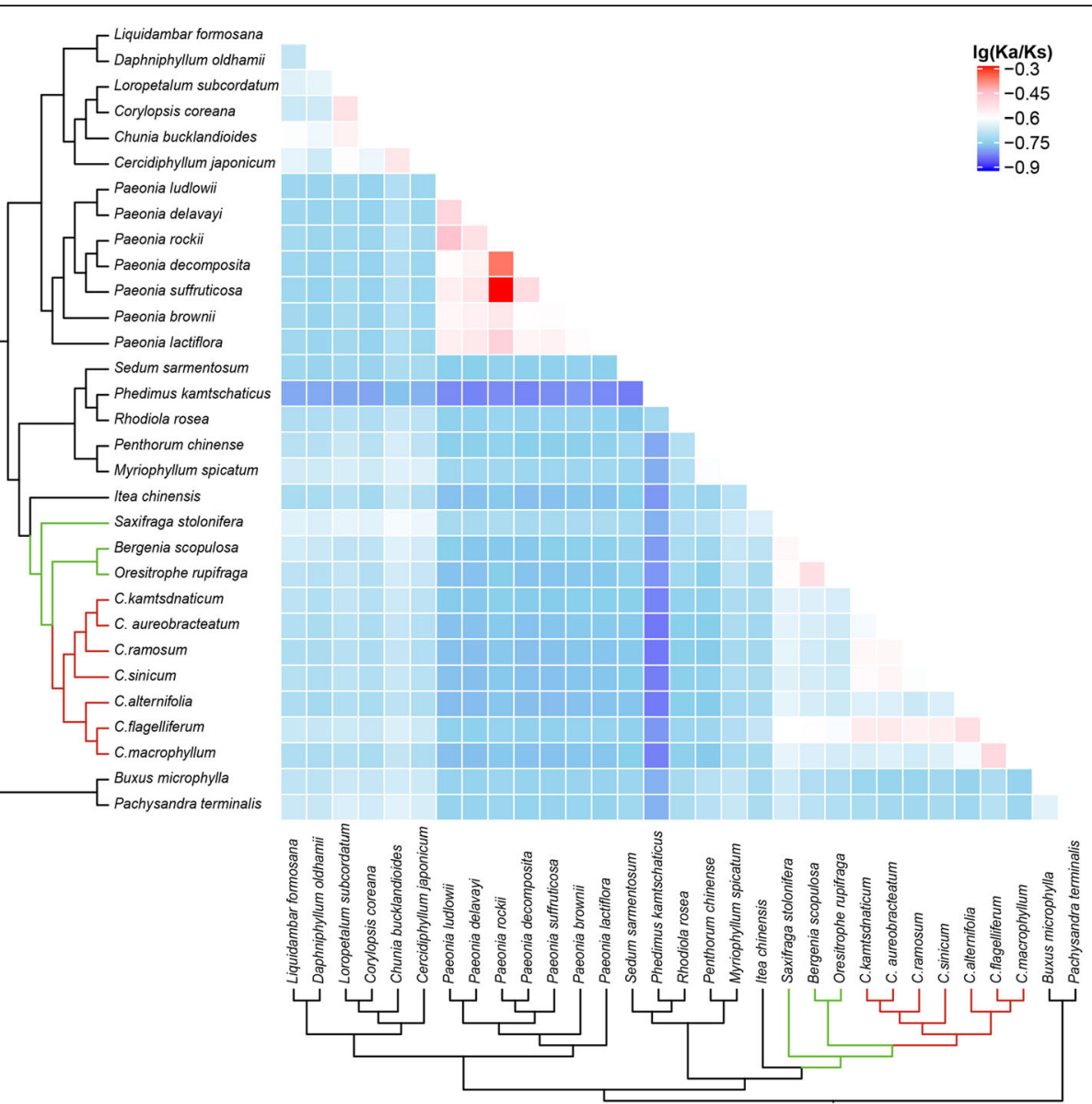

Fig. 5 Pairwise Ka/Ks ratios in Saxifragaceae and other families. This heatmap shows pairwise Ka/Ks ratios between every sequence in the multigene nucleotide alignment. Chrysosplenium is shown on red branches. The scale factors associated with each value are shown on the top right side of the figure

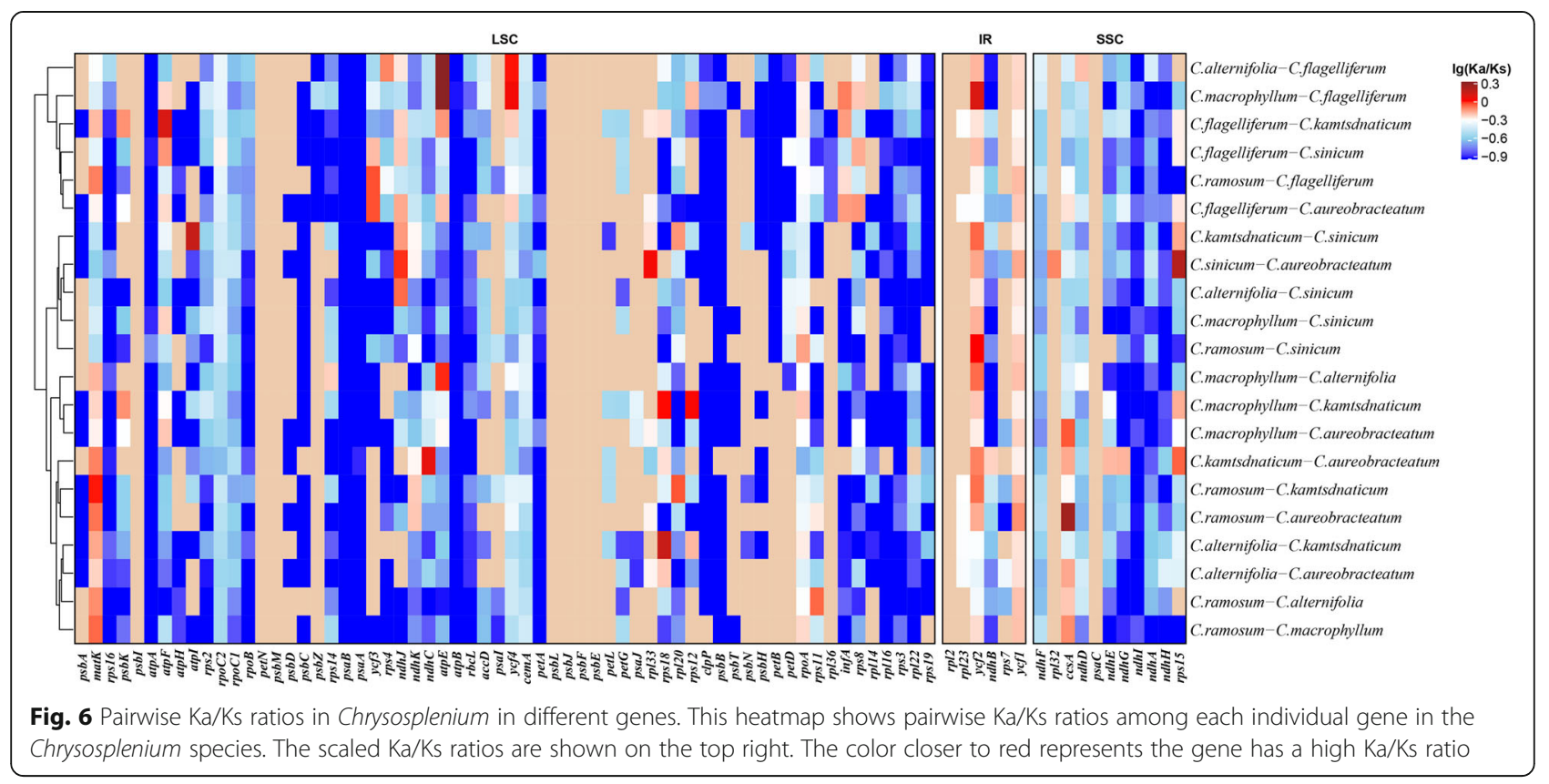



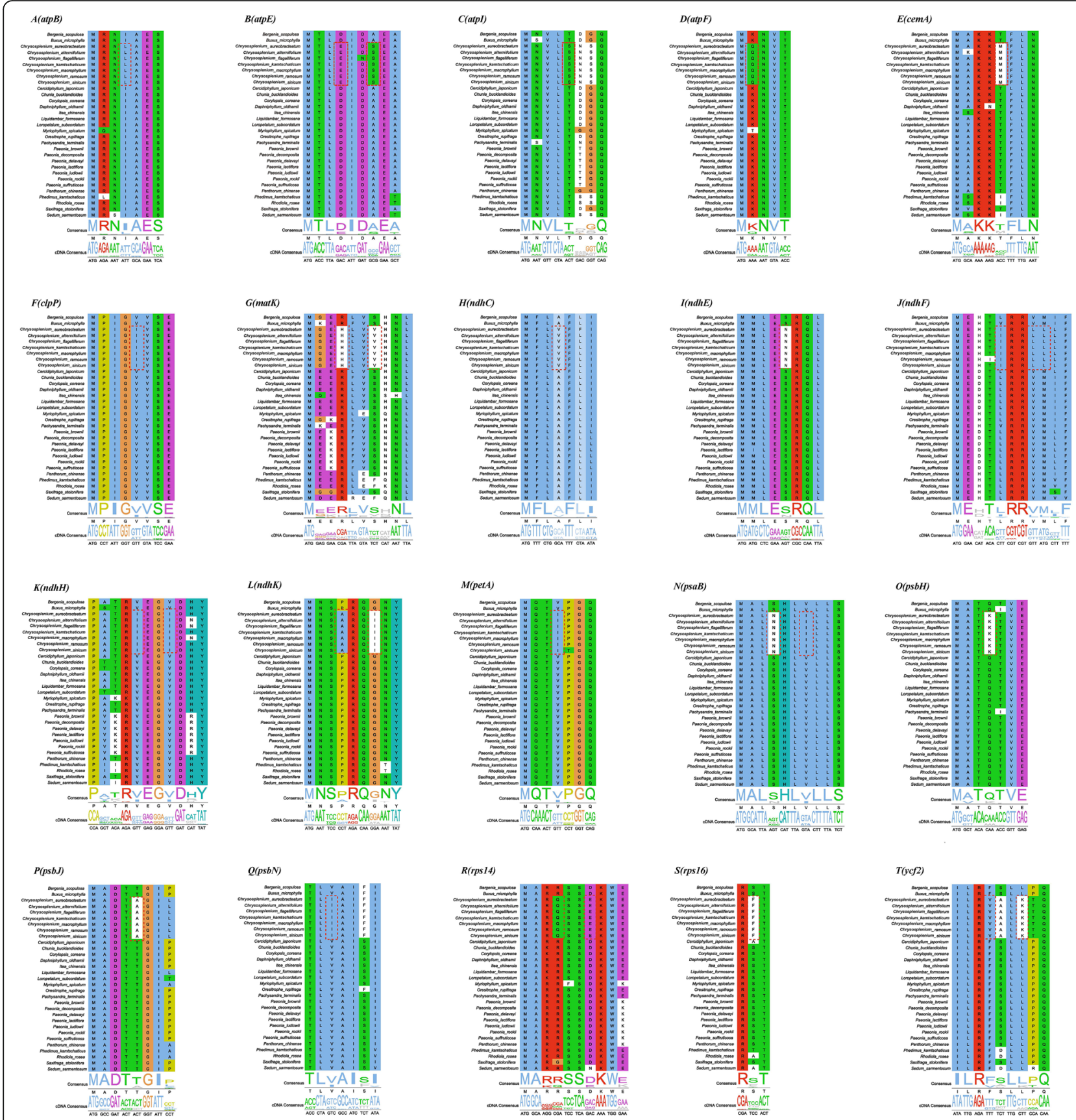

Fig. 7 The partial alignment of 19 genes suggesting sites with positive selection in the BEB test. The red blocks stand for the amino acids in Chrysosplenium with a high BEB posterior probability

most genes were subjected to purifying selection to retain conserved functions in the Chrysosplenium. In the opposite environment, sunlight, including UV radiation, induces DNA damage, mutations and rearrangements [33, 34], which may contribute to an increase in mutation rates. Moreover, it has been proposed that more solar radiation and higher temperatures increase metabolism and growth rates, shortening generation times and increasing mutation rates [35]. Meanwhile, low light is also a stress to the plants which can increase the mutation rates. As one of the most prevalent form in natural selection, purifying selection constantly sweeps away deleterious mutations in population. Therefore, the purifying selection on most chloroplast genes within Chrysosplenium would be evolutionary result of the preservation of the adaptive characteristics of Chrysosplenium species. 


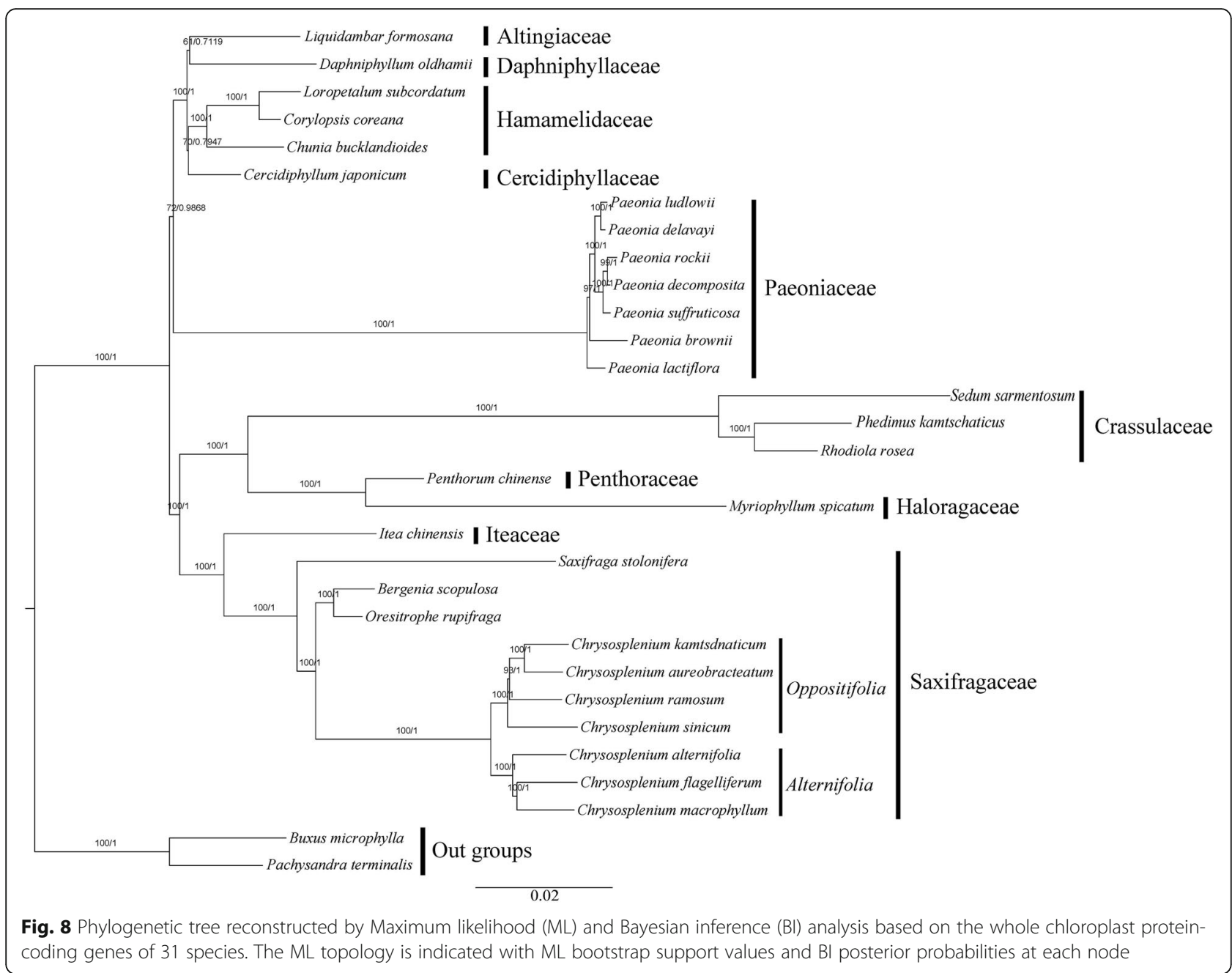

Plants have a variety of strategies to adapt to the environment; therefore, multiple genes may have been subjected to positive selection in Chrysosplenium during its adaptation. The gene matK is transcribed from the sole intact plastid group IIA intron ORF localized between the exons coding for the lysine-tRNA (trnK-UUU). In contrast to other group IIA ORFs, matK has lost domains assigned to a reverse transcriptase and endonuclease function [31, 36]. mat $K$ is usually used as a phylogenetic signal that can resolve evolutionary relationships because of its the high nucleotide and amino acid substitution rates [37, 38]. However, an extremely significant positive selection site at the $117 \mathrm{~S}$ loci in matK of Chrysosplenium suggests this positive selection fixes beneficial variations within Chrysosplenium. The gene $y c f 2$ is the largest chloroplast gene reported in angiosperms [39]. $y c f 2$ has become a useful gene for assessing sequence variation and evolution in plants [40]. Positive selection of $y c f 2$ was also found to be involved in adaptation in other species [41]. However, due to the extremely high $\mathrm{Ka} / \mathrm{Ks}$ value $(=231.51421)$ and unknown function, $y c f 2$ is a valuable resource for future research of the adaptive evolution of Chrysosplenium. Further functional studies on the adaptive amino acid sites of chloroplast genes in Chrysosplenium are needed.

\section{Conclusions}

In this study, we sequenced the chloroplast genomes of six Chrysosplenium species and revealed the chloroplast genomic features between the Oppositifolia (C. macrophyllum, C. flagelliferum, C. alternifolium, and C. ramosum) and Alternifolia (C. ramosum, C. kamtschaticum, and $C$. sinicum) subgenera. In addition, we combined these six sequences with the previously reported chloroplast genomes of C. aureobracteatum (Oppositifolia), $S$. stolonifera (Saxifragaceae), B. scopulosa (Saxifragaceae), and O. rupifraga (Saxifragaceae). We discussed the comprehensive features of the chloroplast genomes, such as gene content and GC content, in these seven species of Chrysosplenium. All the species of Saxifragaceae shared similar genome structures, whereas the seven species of Chrysosplenium showed a lower average GC content, 
indicating selective pressure in their unique habitats. At the chloroplast genome level, the $\mathrm{Ka} / \mathrm{Ks}$ ratios of the individual sequences showed that Chrysosplenium species were subjected to purifying selection compared to the non-Chrysosplenium species. At the level of amino acid sites, we found that $m a t K$ and $y c f 2$ were under positive selection with both high posterior probability and statistical significance. Other 15 genes with lower posterior probability involved in photosynthesis out of 19 were also possibly subjected to positive selection via a change of amino acid sites, which may be the adaptive response to its moist and shaded habitat. Using the proteincoding sequences from the whole chloroplast genome of 31 species, the robust consensus of phylogenetic trees reconstructed with both $\mathrm{ML}$ and BI algorithms suggested that Chrysosplenium species are sister to B. scopulosa and $O$. rupifraga within Saxifragaceae of Saxifragales. Also, our results supported the classification of the genus into two subgenera based on the morphology of opposite leaves or alternate leaves. These findings will be valuable for further study of the chloroplast genomes of Chrysosplenium species and provide valuable resources for studies of plant adaptation to low light conditions.

\section{Methods}

\section{Sampling and sequencing}

To represent the Chrysosplenium, six species were selected based on their morphological characteristics: $C$. macrophyllum, C. flagelliferum, and C. alternifolium belonging to the Alternifolia subgenus, and C. ramosum, C. kamtschaticum, and C. sinicum belonging to the Oppositifolia subgenus. Among the six species from wild, three were collected from China and three were from Japan (See details in Additional File 2: Supplementary Table S1). Due to a high content of secondary metabolites, the chloroplast DNA of C. macrophyllum was extracted using a high-salt method [42]. To get a complete chloroplast genome, which can be used as a reference in assembling chloroplast genome of the other five species, C. macrophyllum was sequenced using the PacBio Sequel I platform at Frasergen (Wuhan, China) and the Illumina Hiseq 2500 at the Novogene Company (Beijing, China). The total genomic DNA for the other five Chrysosplenium species was extracted using a modified cetyltrimethylammonium bromide (CTAB) method [43] and sequenced using the Illumina Hiseq 2500 platform at the Novogene Company (Beijing, China).

\section{Chloroplast genome assembly and annotation}

The sequencing of the chloroplast DNA of C. macrophyllum with the PacBio Sequel I platform generated 218,330 reads with the N50 of $4452 \mathrm{bp}$. De novo genome assembly was conducted using Canu (v1.5) [44], which produced 4028 contigs with an N50 of $5011 \mathrm{bp}$. To discard nuclear DNA sequences, we aligned the contigs to a whole-chloroplast reference genome with the BurrowWheeler Aligner bwa [45]. Then the contigs were polished with Arrow implemented in SMRT Link v6.0.0. Finally, the draft chloroplast genome was manually adjusted based on the two inverted repeats and scaffolds assembled from the Illumina Hiseq 2500 platform.

Sequence data for the other five species generated from the Illumina Hiseq 2500 platform were processed to remove the low-quality reads and adaptors. The clean reads were aligned to the complete chloroplast genome of $C$. macrophyllum with bwa-0.7.12 [45]. The aligned reads were then selected for de novo assembly with ABYSS2.0.2 [46] after the optimal K-mer was chosen with the software kmergenie [47]. Then, the contigs were connected with Sequencher 5.4.6 and scaffolded again with the original data by the software SSPACE_Standard_v3.0 [48]. Last, the assembled scaffolds were manually adjusted based on the two inverted repeats and verified by Sanger sequencing (Additional File 2: Supplementary Table S2). We also assembled these scaffolds with GetOrganelle [49] to validate the ones assembled with ABYSS-2.0.2.

Gene annotation was performed using CPGAVAS2 [50] and PGA [51]. The different annotations of proteincoding sequences were confirmed using BLASTx. The tRNAs were checked with tRNAscan-SE v2.0.3 [52]. Final chloroplast genome maps were drawn using OGDRAW [53].

To identify the nuclear homologs of chloroplast rpl32 (Cp_rpl32) in $C$. sinicum, the protein sequence of $C p_{-}$ rpl32 was subjected to a BLASTp analysis against our the whole protein sequences from our nuclear genome of $C$. sinicum with the threshold of $30 \%$ identity, and the nuclear rpl32 genes were further annotated via the BLASTp of these potential nuclear homologs against NCBI non-redundant protein database with the threshold of $30 \%$ identity and an e-value $<1 \mathrm{E}-10$.

\section{Analysis of GC content, nucleotide diversity, and repeat content}

We accessed chloroplast genome sequences of Chrysosplenium aureobracteatum (MG878089; Saxifragaceae; Chrysosplenium), Saxifraga stolonifera (MH191389; Saxifragaceae; Saxifraga), Bergenia scopulosa (KY412195; Saxifragaceae; Bergenia), and Oresitrophe rupifraga (MF774190; Saxifragaceae; Oresitrophe) from GenBank to compare the features among these chloroplast genomes in Saxifragaceae. The nucleotide diversity (Pi) among the seven species of Chrysosplenium was calculated using the software DnaSP v6.12.03 [54]. The GC content of the whole chloroplast genome and the third position GC content of codons for all ten species were calculated using an in-house Python script. The simple 
sequence repeats (SSRs) were detected using the MIcroSAtellite (MISA) identification tool with the minimum repeat number set at 10, 5, 4, 3, 3, and 3 for mono-, di-, tri-, tetra-, penta-, and hexanucleotides, respectively. We also identified tandem repeat sequences using REPuter [55] with minimal repeats of more than $30 \mathrm{bp}$ and hamming distances of less than $3 \mathrm{bp}$.

\section{Boundary regions and comparative analysis}

The contraction or expansion between boundary regions of the chloroplast genome in each species was drawn by IRscope [56]. To compare the conservation of each gene, we visualized the results with mVISTA through two alignment programs: LAGAN, which produces true multiple alignments regardless of whether they contain inversions or not, and Shuffle-LAGAN, which can detect rearrangements and inversions in sequences [57].

\section{Selective pressure estimation}

We carried out selective pressure estimation for the 6 species of Chrysosplenium and 25 species of non-Chrysosplenium with two strategies: calculation based on pairwise comparison and calculation based on the branch-site model:

All protein-coding sequences (CDSs) from each of the 31 species were concatenated into a super matrix for inferring phylogenetic tree. Then, species vs. species $\mathrm{Ka} / \mathrm{Ks}$ ratio was estimated. In addition, the $\mathrm{Ka} / \mathrm{Ks}$ ratio was estimated for each of the 79 genes within Chrysosplenium separately. The CDS for each gene was translated to amino acid sequences, which were aligned with MEGA7 [58]. Then, the corresponding CDS were aligned according to the amino acid sequences. Lastly, $\mathrm{Ka} / \mathrm{Ks}$ ratios were calculated using the KaKs-calculator v 2.0 [59]. Genes with $1<\mathrm{Ka} / \mathrm{Ks}$ ratio $<45$ were considered as under positive selection; genes with $\mathrm{Ka} / \mathrm{Ks}$ ratio $<1$ were considered as under purifying selection. The ratio $>=45$ or NA indicates that the gene has few nonsynonymous sites/substitutions, and was not considered in our analysis.

A total of 66 CDSs presented in all the analysed species, and were used for identification of positive selection using the branch-site model [32]. CDSs of each gene were aligned according to their amino acid sequences with MEGA7 [58]. The branch-site model in the program codeml of the PAML v4.9 package [60] was used to assess potential positive selection in Chrysosplenium that was set as the foreground branch. Selective pressure is measured by the ratio $(\omega)$ of the nonsynonymous substitution rate $(\mathrm{dN})$ to the synonymous substitutions rate (dS). A neutral branch-site model (Model $=2$, NSsites $=$ 2, Fix $=1$, and Fix $\omega=1$ ) and an alternative branch-site model (Model $=2$, NSsites $=2$, and Fix $=0$ ) were applied separately. The right-tailed Chi-square test was used to compute $p$-values based on the difference of log- likelihood values between the two models with one degree of freedom. Moreover, BEB method [61] was implemented to calculate the posterior probabilities for amino acid sites that are potentially under positive selection. A gene with a $p$-value $<0.05$ and $\omega>1$ was considered as a positively selected gene. An amino acid site with posterior probabilities $>0.95$ was considered as positively selected.

\section{Phylogenetic analyses}

To construct a phylogeny of Chrysosplenium, 29 species of Saxifrageles and two Buxaceae species (as outgroups) were selected (see Additional file 2: Supplementary Table S3 for details). The whole-chloroplast proteincoding genes of these 31 species were aligned with MUSCLE v3.8.31 [62]. The best-fitting nucleotide substitution model was determined using the Akaike Information Criterion in the model-finder IQ-TREE [63]. ML analysis was performed using IQ-TREE with the best model of GTR + F+R4 and 1000 bootstrap replicates, and BI analysis was performed in MrBayes 3.2.6 [64] using the Markov Chain Monte Carlo method with 200, 000 generations and sampling trees every 100 generations. The first $20 \%$ of trees were discarded as burn-in with the remaining trees being used for generating a consensus tree.

\section{Supplementary information}

Supplementary information accompanies this paper at https://doi.org/10. 1186/s12864-020-07045-4.

Additional File 1 The protein sequences (A) and expression values in leaf (B) of both chloroplast rp/32 (Cp_rp/32) and its nuclear homolog (Nu_rpl32) in C. sinicum.

Additional File 2. Supplementary Tables S1-S6.

Additional File $\mathbf{3}$ Comparison of nucleotide diversity ( $\mathrm{Pi}$ ) between the chloroplast genomes of Chrysosplenium.

Additional File 4. Supplementary Tables S7-S11.

Additional File 5. Analyses of repeat sequences in the ten species of Saxifragaceae. (A) The analysis of simple sequence repeats (SSRs) in chloroplast genomes of Saxifragaceae. (B) The repeat types in Saxifragaceae.

Additional File 6. The comparative analysis with Shuffle-LAGAN program of the whole chloroplast genome of seven different species from the family of Saxifragaceae.

\footnotetext{
Abbreviations

LSC: Large single copy region; IR: Inverted repeat region; SSC: Small single copy region; PCR: Polymerase chain reaction; tRNAs: Transport RNAs;

rRNAs: Ribosomal RNAs; Ka/Ks: The rate of non-synonymous substitutions to the rate of synonymous substitutions; SSRs: Simple sequence repeats; ML: Maximum likelihood; BI: Bayesian inference; BEB: Bayes empirical bayes; IGS: Intergenic spacer region; FPKMs: Fragments per kilobase of exon per million reads
}

Acknowledgements

Not applicable. 


\section{Authors' contributions}

$Z W, R L$, and $H L$ conceived and designed the experiments. RL, TY, XD and DL performed the experiments. $Z W$ and $R L$ analyzed the data. $Z W, R L, R Q$, and $\mathrm{HL}$ wrote the paper. All authors have read and approved the manuscript.

\section{Funding}

This work was supported by the Construction Plan of Hubei Province Science and Technology basic conditions platform (No. 2017BEC014), Fund for Key Laboratory Construction of Hubei Province (No. 2018BFC360) and Hubei Provincial Natural Science Foundation of China (No. 2019CFB214). All funders we mentioned provide financial support for our study.

\section{Availability of data and materials}

All chloroplast genomes used in this study can be found in Genbank and their Genbank accessions can be found in Additional File 2: Supplementary Table S1 and Additional File 2: Supplementary Table S3. The whole protein sequences of the nuclear genome of C. sinicum in our study are archived at the Dryad Digital Repository (https://doi.org/10.5061/dryad.jdfn2z38m). The other data sets generated in this study are included within the article and additional files. All materials used or generated during the study are kept in our laboratory. Most figures were completed by the open source software, R package; some figures were done by the relevant software with the proper citations.

\section{Ethics approval and consent to participate}

Not applicable. The plant was collected in non protected area; no any legal authorization/license is required.

\section{Consent for publication}

Not applicable.

\section{Competing interests}

The authors declare that they have no competing interests.

\section{Author details}

${ }^{1}$ Hubei Provincial Key Laboratory for Protection and Application of Special Plant Germplasm in Wuling Area of China, Key Laboratory of State Ethnic Affairs Commission for Biological Technology, College of Life Sciences, South-Central University for Nationalities, Wuhan 430074, Hubei, China. ${ }^{2}$ CAS Key Laboratory of Plant Germplasm Enhancement and Specialty Agriculture, Wuhan Botanical Garden, Chinese Academy of Sciences, Wuhan 430074, Hubei, China.

Received: 27 May 2020 Accepted: 1 September 2020 Published online: 10 September 2020

\section{References}

1. Wu Z, Gui S, Quan Z, Pan L, Wang S, Ke W, Liang D, Ding Y. A precise chloroplast genome of Nelumbo nucifera (Nelumbonaceae) evaluated with sanger, lllumina MiSeq, and PacBio RS II sequencing platforms: insight into the plastid evolution of basal eudicots. BMC Plant Biol. 2014;14:289.

2. Alzahrani DA, Yaradua SS, Albokhari EJ, Abba A. Complete chloroplast genome sequence of Barleria prionitis, comparative chloroplast genomics and phylogenetic relationships among Acanthoideae. BMC Genomics. 2020; 21(1):393.

3. Cui L, Leebens-Mack J, Wang L, Tang J, Rymarquis L, Stern DB, Claude WD. Adaptive evolution of chloroplast genome structure inferred using a parametric bootstrap approach. BMC Evol Biol. 2006;6:13.

4. Scott-Phillips TC, Laland KN, Shuker DM, Dickins TE, West SA. The niche construction perspective: a critical appraisal. Evolution. 2014;68(5):1231-43.

5. R. Marcelino V, MCM C, Jackson CJ, AAW L, Verbruggen H. Evolutionary dynamics of chloroplast genomes in low light: a case study of the endolithic green alga Ostreobium quekettii. Genome Biol Evol. 2016;8(9): 2939-51.

6. The Angiosperm Phylogeny G. An update of the angiosperm phylogeny group classification for the orders and families of flowering plants: APG IV. Bot J Linn Soc. 2016;181(1):1-20.

7. POWO. Plants of the world online. In: facilitated by the Royal Botanic Gardens. Kew: Published on the Internet; 2019. http://powo.science.kew.org/ taxon/urn:Isid:ipni.org:names:30129301-30129302\#children.
8. Hara H. Synopsis of the genus Chrysosplenium L. J Fac Sci Univ Tokyo. 1957; 3(7):1-90.

9. Soltis DE, Tago-Nakazawa M, Xiang Q-Y, Kawano S, Murata J, Wakabayashi M, Hibsch-Jetter C. Phylogenetic relationships and evolution in Chrysosplenium (Saxifragaceae) based on matK sequence data. Am J Bot. 2001;88(5):883-93.

10. Pan J, Ohba H. Chrysosplenium. In: Wu ZY, Raven PH, editors. Flora of China, vol. 8. Beijing and St. Louis: Science press and Missouri botanical garden press; 2001. p. 346-58.

11. Liu H, Luo J, Liu Q, Lan D, Qin R, Yu X. A new species of Chnysosplenium (Saxifragaceae) from Zhangjiajie, Hunan, Central China. Phytotaxa. 2016;277:287-92.

12. Franchet A. Monographie du genere Chrysosplenium tourn. Nouv Arch duMuséum Hist Nat. 1891;3(2):1-32.

13. Guo Q, Ricklefs R, Cody M. Vascular plant diversity in eastern Asia and North America: historical and ecological explanations. Bot J Linn Soc. 1998;128(2):123-36.

14. Xiang QY, Zhang WH, Ricklefs RE, Qian H, Chen ZD, Wen J, Li JH. Regional differences in rates of plant speciation and molecular evolution: a comparison between eastern Asia and eastern North America. Evolution. 2004;58(10):2175-84.

15. Ibrahim K, De Luca V, He K, Latchinian L, Brisson L, Charest PM. Enzymology and compartmentation of polymethylated flavonol glucosides in Chrysosplenium americanum. Phytochemistry. 1987;26:1237-45.

16. Han J, Yang S, Kim H, Jang C, Park J, Kang S. Phylogenetic study of Korean Chrysosplenium based on nrDNA ITS sequences. Korean J Plant Resour. 2011; 24(4):358-69.

17. Kim Y, Kim Y. Molecular systematic study of Chrysosplenium series pilosa (Saxifragaceae) in Korea. J Plant Biol. 2011;54(6):396.

18. Ravi V, Khurana JP, Tyagi AK, Khurana P. An update on chloroplast genomes Plant Syst Evol. 2008;271(1):101-22.

19. Parks M, Cronn R, Liston A. Increasing phylogenetic resolution at low taxonomic levels using massively parallel sequencing of chloroplast genomes. BMC Biol. 2009;7:84.

20. Xie D, Yu H, Price M, Xie C, Deng Y, Chen J, Yu Y, Zhou S, He X. Phylogeny of chinese Allium species in section daghestanica and adaptive evolution of Allium (Amaryllidaceae, Allioideae) species revealed by the chloroplast complete genome. Front Plant Sci. 2019;10:460.

21. Kim Y, Lee J, Kim Y. The complete chloroplast genome of a Korean endemic plant Chrysosplenium aureobracteatum Y.I. Kim \& Y.D. Kim (Saxifragaceae). Mitochondrial DNA Part B. 2018;3:380-1.

22. Huang $C Y$, Ayliffe MA, Timmis JN. Direct measurement of the transfer rate of chloroplast DNA into the nucleus. Nature. 2003;422(6927):72-6.

23. Stegemann S, Hartmann S, Ruf S, Bock R. High-frequency gene transfer from the chloroplast genome to the nucleus. Proc Natl Acad Sci. 2003;100(15):8828.

24. Park S, Jansen RK, Park S. Complete plastome sequence of Thalictrum coreanum (Ranunculaceae) and transfer of the rp/32 gene to the nucleus in the ancestor of the subfamily Thalictroideae. BMC Plant Biol. 2015;15(1):40.

25. Ueda M, Fujimoto M. Arimura S-i, Murata J, Tsutsumi N, Kadowaki K-i. loss of the rp/32 gene from the chloroplast genome and subsequent acquisition of a preexisting transit peptide within the nuclear gene in Populus. Gene. 2007:402(1):51-6.

26. Cusack BP, Wolfe KH. When gene marriages don't work out: divorce by subfunctionalization. Trends Genet. 2007;23(6):1208-13.

27. Fleischmann TT, Scharff LB, Alkatib S, Hasdorf S, Schöttler MA, Bock R. Nonessential plastid-encoded ribosomal proteins in tobacco: a developmental role for plastid translation and implications for reductive genome evolution. Plant Cell. 2011;23(9):3137-55.

28. Charlesworth B. Genetic recombination: patterns in the genome. Curr Biol. 1994;4(2):182-4.

29. Foerstner KU, von Mering C, Hooper SD, Bork P. Environments shape the nucleotide composition of genomes. EMBO Rep. 2005;6(12):1208-13.

30. Jia Q, Wu H, Zhou X, Gao J, Zhao W, Aziz J, Wei J, Hou L, Wu S, Zhang Y, et al. A "GC-rich" method for mammalian gene expression: a dominant role of non-coding DNA GC content in regulation of mammalian gene expression. Sci China Life Sci. 2010;53(1):94-100.

31. Wicke S, Schneeweiss GM. dePamphilis CW, Müller KF, Quandt D. the evolution of the plastid chromosome in land plants: gene content, gene order, gene function. Plant Mol Biol. 2011;76(3):273-97.

32. Yang Z, Wong WSW, Nielsen R. Bayes empirical bayes inference of amino acid sites under positive selection. Mol Biol Evol. 2005;22(4):1107-18.

33. Raven JA, Beardall J, AWD L, Sánchez-Baracaldo P. Interactions of photosynthesis with genome size and function. Philos Trans R Soc Lond B Biol Sci. 2013;368(1622):20120264. 
34. Kumar RA, Oldenburg DJ, Bendich AJ. Changes in DNA damage, molecular integrity, and copy number for plastid DNA and mitochondrial DNA during maize development. J Exp Bot. 2014;65(22):6425-39.

35. Klaus R. Latitudinal gradients in species diversity: the search for the primary cause. Oikos. 1992;65:514-27.

36. Liere $\mathrm{K}$, Link $\mathrm{G}$. RNA-binding activity of the matK protein encodecd by the chloroplast trnk intron from mustard ( Sinapis alba L.). Nucleic Acids Res. 1995;23(6):917-21.

37. Hilu KW, Borsch T, Müller K, Soltis DE, Soltis PS, Savolainen V, Chase MW, Powell MP, Alice LA, Evans R, et al. Angiosperm phylogeny based on matK sequence information. Am J Bot. 2003;90(12):1758-76.

38. Hilu KW, Liang G. The matK gene: sequence variation and application in plant systematics. Am J Bot. 1997;84(6):830-9.

39. Drescher A, Ruf S, Calsa T Jr, Carrer H, Bock R. The two largest chloroplast genome-encoded open reading frames of higher plants are essential genes. Plant J. 2000;22(2):97-104.

40. Huang J, Sun G, Zhang D. Molecular evolution and phylogeny of the angiosperm ycf2 gene. J Syst Evol. 2010;48(4):240-8.

41. Zhong Q, Yang S, Sun X, Wang L, Li Y. The complete chloroplast genome of the Jerusalem artichoke (Helianthus tuberosus L.) and an adaptive evolutionary analysis of the ycf2 gene. PeerJ. 2019;7:e7596.

42. Shi C, Hu N, Huang H, Gao J, Zhao Y, Gao L An improved chloroplast DNA extraction procedure for whole plastid genome sequencing. PLoS One. 2012;7(2):e31468.

43. Doyle J. DNA protocols for plants-CTAB total DNA isolation. Mol Tech Taxonomy. 1991:57:283-93.

44. Koren S, Walenz BP, Berlin K, Miller JR, Bergman NH, Phillippy AM. Canu: scalable and accurate long-read assembly via adaptive k-mer weighting and repeat separation. Genome Res. 2017;27(5):722-36.

45. Li H, Durbin R. Fast and accurate long-read alignment with burrowswheeler transform. Bioinformatics. 2010;26(5):589-95.

46. Jackman SD, Vandervalk BP, Mohamadi H, Chu J, Yeo S, Hammond SA, Jahesh G, Khan H, Coombe L, Warren RL, et al. ABySS 2.0: resource-efficient assembly of large genomes using a bloom filter. Genome Res. 2017;27(5):768-77.

47. Chikhi R, Medvedev P. Informed and automated k-mer size selection for genome assembly. Bioinformatics. 2013;30(1):31-7.

48. Boetzer M, Henkel CV, Jansen HJ, Butler D, Pirovano W. Scaffolding preassembled contigs using SSPACE. Bioinformatics. 2010;27(4):578-9.

49. Jin J, Yu W, Yang J, Song Y, Yi T, Li D. GetOrganelle: a simple and fast pipeline for de novo assembly of a complete circular chloroplast genome using genome skimming data. bioRxiv. 2018. https://doi.org/10.1101/ 256479

50. Shi $L$, Chen $H$, Jiang $M$, Wang $L$, Wu X, Huang L, Liu C. CPGAVAS2, an integrated plastome sequence annotator and analyzer. Nucleic Acids Res. 2019;47(W1):W65-73

51. Qu X, Moore MJ, Li D, Yi T. PGA: a software package for rapid, accurate, and flexible batch annotation of plastomes. Plant Methods. 2019;15(1):50.

52. Schattner P, Brooks AN, Lowe TM. The tRNAscan-SE, snoscan and snoGPS web servers for the detection of tRNAs and snoRNAs. Nucleic Acids Res. 2005;33(suppl_2):W686-9.

53. Greiner $S$, Lehwark P, Bock R. OrganellarGenomeDRAW (OGDRAW) version 1. 3.1: expanded toolkit for the graphical visualization of organellar genomes. Nucleic Acids Res. 2019:47(W1):W59-64.

54. Rozas J, Ferrer-Mata A, Sánchez-DelBarrio JC, Guirao-Rico S, Librado P, Ramos-Onsins SE, Sánchez-Gracia A. DnaSP 6: DNA sequence polymorphism analysis of large data sets. Mol Biol Evol. 2017;34(12):3299-302.

55. Kurtz S, Choudhuri JV, Ohlebusch E, Schleiermacher C, Stoye J, Giegerich R. REPuter: the manifold applications of repeat analysis on a genomic scale. Nucleic Acids Res. 2001;29(22):4633-42.

56. Amiryousefi A, Hyvönen J, Poczai P. IRscope: an online program to visualize the junction sites of chloroplast genomes. Bioinformatics. 2018;34(17):3030-1.

57. Brudno M, Do CB, Cooper GM, Kim MF, Davydov E, Program NCS, Green ED, Sidow A, Batzoglou S. Lagan and multi-Lagan: efficient tools for large-scale multiple alignment of genomic DNA. Genome Res. 2003;13(4):721-31.

58. Kumar S, Stecher G, Tamura K. MEGA7: molecular evolutionary genetics analysis version 7.0 for bigger datasets. Mol Biol Evol. 2016;33(7):1870-4.

59. Wang D, Zhang Y, Zhang Z, Zhu J, Yu J. KaKs_Calculator 2.0: a toolkit incorporating gamma-series methods and sliding window strategies. Genomics Proteomics Bioinformatics. 2010;8(1):77-80.

60. Yang Z. PAML 4: phylogenetic analysis by maximum likelihood. Mol Biol Evol. 2007;24(8):1586-91.
61. Yang Z, dos Reis M. Statistical properties of the branch-site test of positive selection. Mol Biol Evol. 2010;28(3):1217-28.

62. Edgar RC. MUSCLE: multiple sequence alignment with high accuracy and high throughput. Nucleic Acids Res. 2004;32(5):1792-7.

63. Nguyen L, Schmidt HA, von Haeseler A, Minh BQ. IQ-TREE: a fast and effective stochastic algorithm for estimating maximum-likelihood phylogenies. Mol Biol Evol. 2014;32(1):268-74.

64. Ronquist F, Teslenko M, van der Mark P, Ayres DL, Darling A, Höhna S, Larget B, Liu L, Suchard MA, Huelsenbeck JP. MrBayes 3.2: efficient Bayesian phylogenetic inference and model choice across a large model space. Syst Biol. 2012;61(3):539-42

\section{Publisher's Note}

Springer Nature remains neutral with regard to jurisdictional claims in published maps and institutional affiliations.
Ready to submit your research? Choose BMC and benefit from:

- fast, convenient online submission

- thorough peer review by experienced researchers in your field

- rapid publication on acceptance

- support for research data, including large and complex data types

- gold Open Access which fosters wider collaboration and increased citations

- maximum visibility for your research: over $100 \mathrm{M}$ website views per year

At BMC, research is always in progress.

Learn more biomedcentral.com/submissions 